CLINICAL IMAGE

\title{
Bacillary Angiomatosis of the Upper Lip
}

\author{
Christina Avila ${ }^{1}$, Stephanie Trovat ${ }^{2}$, Catherine Chung ${ }^{2}$, Benjamin Kaffenberger ${ }^{1,2}$ \\ ${ }^{1}$ The Ohio State University College of Medicine, Columbus OH, USA \\ ${ }^{2}$ The Ohio State University Medical Center, Division of Dermatology, Columbus, OH, USA
}

\begin{abstract}
Bacillary angiomatosis is the development of vascular-rich papules and nodules in response to proliferation of bacteria from the genus Bartonella. We report a case of bacillary angiomatosis in an HIV-infected male that presented as firm, vascular papules on the upper lip recalcitrant to prior treatments. Histopathologic examination showed an inflammatory infiltrate surrounding vascular proliferation and Warthin Starry Stain revealed numerous rod-shaped organisms. Serologies were positive for $B$. henselae $\operatorname{lgG}$ and resolution occurred following treatment with oral antibiotics. J Microbiol Infect Dis 2021; 11(2):114-115.
\end{abstract}

Keywords: Bacillary angiomatosis, Bartonella spp., HIV infection

\section{CASE SUMMARY}

A 38-year-old man with HIV and a CD4 count of 43 cells/ $\mu$ reported a four-month history of an exophytic growth on the right upper lip associated with fevers and fatigue. Previous attempts at removal include silver nitrate treatment and excision three months prior. Physical examination revealed firm vascular red coalescing papulo-nodules with overlying crust and surrounding inflammation on the right upper lip (Figure 1) and associated cervical lymphadenopathy. A skin shave biopsy was performed. Pathology demonstrated an ulcerated nodule with dermal inflammation and hemorrhage at scanning magnification and higher power revealed a proliferation of smallcaliber vessels associated with a mixed inflammatory infiltrate with neutrophils. Warthin Starry Stain highlighted numerous rod-shaped organisms (Figure 2). Serology was positive for $B$. henselae IgG $(1: 256)$ and negative for $\lg \mathrm{M}$. The diagnosis of bacillary angiomatosis (BA) was made. The patient was treated with azithromycin with resolution by six weeks.

$B A$ is an exanthem of systemic infection by Bartonella species ( $B$. henselae or $B$. quintana), an angioproliferative gram-negative rod transmitted through cat scratches, bites, or fleas, or the human body louse [1-3]. Cutaneous BA is most common and manifests as red or purple vascular nodules, however life-threatening disease can occur in extra-cutaneous involvement in the brain, respiratory system, gastrointestinal tract, bone and lymph nodes [1]. Diagnosis is confirmed via tissue biopsy with histologic examination.

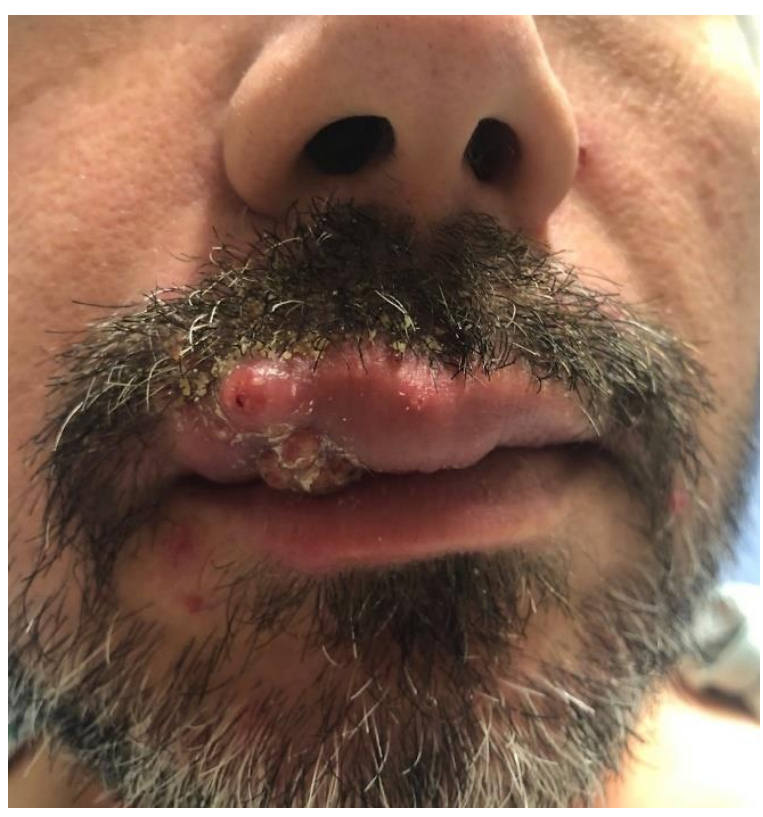

Figure 1. Bacillary angiomatosis of the upper lip. Vascular red coalescing papulo-nodules with overlying crust and surrounding areas of inflammation on the right upper lip. 
Histological examination shows vascular proliferation and plump endothelial cells infected with bacteria identified by Wartharin-Starry stain [1]. Treatment consists of long-term macrolide antibiotics; local excision is unnecessary as the lesion quickly recurs [2].

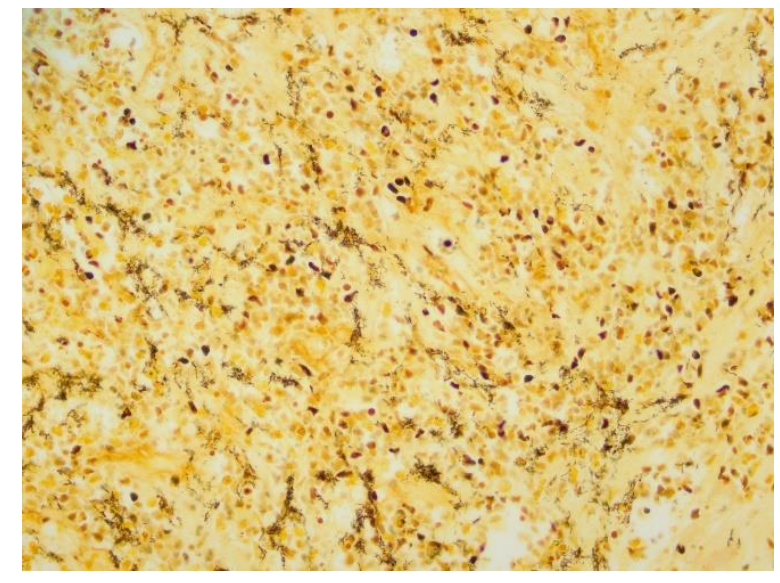

Figure 2. Warthin Starry Stain. (x400) Highlighting numerous clumps of rod-shaped organisms.

\section{ACKNOWLEDGMENTS}

Declaration of Conflicting Interests: The authors declare that they have no conflict of interest.

Financial Disclosure: No financial support was received.

\section{REFERENCES}

1.Moulin C, Kanitakis J, Ranchin B, et al. Cutaneous bacillary angiomatosis in renal transplant recipients: Report of three new cases and literature review. Transpl Infect Dis 2012; 14(4):403-409.

2.Cockerell CJ, LeBoit PE. Bacillary angiomatosis: A newly characterized, pseudoneoplastic, infectious, cutaneous vascular disorder. J American Acad Dermatol 1990; 22(3):501-12.

3.Akram SM, Anwar MY, Thandra KC, Rawla P. Angiomatosis, Bacillary. StatPearls, 2021. https://www.ncbi.nlm.nih.gov/books/NBK448092/ 